\title{
Loss of the androgen receptor suppresses intrarenal calcium oxalate crystals deposition via altering macrophage recruitment/M2 polarization with change of the miR-185-5p/CSF-1 signals
}

Wei Zhu ${ }^{1,2}$, Zhijian Zhao ${ }^{1,2}$, Fuju Chou², Li Zuo ${ }^{2}$, Tongzu Liu², Shuyuan Yeh², David Bushinsky ${ }^{3}$, Guohua Zeng ${ }^{1}$ and Chawnshang Chang ${ }^{2,4}$

\begin{abstract}
Crystals can trigger a wide range of kidney injuries that may link to the development of kidney stones. Infiltrating macrophages may influence hyperoxaluria-induced intrarenal calcium oxalate $(\mathrm{CaOx})$ crystals deposition, yet their linkage to sex hormones remains unclear. Here we demonstrated that suppressing the androgen receptor (AR) expression in renal tubular epithelial cells increased the macrophage recruitment/M2 polarization that may result in enhancing the phagocytosis of intrarenal $\mathrm{CaOx}$ crystals. Mechanism dissection suggested that AR can suppress macrophage colony-stimulating factor 1 (CSF-1) expression via increasing miRNA-185-5p expression to suppress the M2 macrophage polarization-mediated intrarenal $\mathrm{CaOx}$ crystals phagocytosis. The preclinical study using glyoxylateinduced intrarenal $\mathrm{CaOx}$ crystals deposition mouse model revealed that renal tubule-specific AR knockout mice have less intrarenal $\mathrm{CaOx}$ crystals deposition with more recruited M2 macrophages in the kidney compared with the wildtype mice. Results from the in vivo rat model using hydroxy---proline-induced $\mathrm{CaOx}$ crystals deposition also demonstrated that targeting the AR with ASC-J9 ${ }^{\circledR}$ suppressed the intrarenal $\mathrm{CaOx}$ crystals deposition via increasing the renal macrophage recruitment/M2 polarization. Together, results from multiple preclinical studies using multiple in vitro cell lines and in vivo mouse/rat models all demonstrated that targeting the AR with a small molecule ASC-J9 ${ }^{\circledR}$ may function via altering macrophage recruitment/M2 polarization to decrease the intrarenal $\mathrm{CaOx}$ crystals deposition, a key phenotype seen in many kidney stone disease patients with hyperoxaluria.
\end{abstract}

Correspondence: Guohua Zeng (gzgyzgh@vip.sina.com) or

Chawnshang Chang (chang@urmc.rochester.edu)

'Department of Urology and Guangdong Key Laboratory of Urology, The First Affiliated Hospital of Guangzhou Medical University, 510230 Guangzhou, China ${ }^{2}$ George Whipple Lab for Cancer Research, Departments of Pathology, Urology, and Radiation Oncology, and The Wilmot Cancer Institute, University of Rochester Medical Center, Rochester, NY 14646, USA

Full list of author information is available at the end of the article. These authors contributed equally: Wei Zhu, Zhijian Zhao, Fuju Chou Edited by A. Linkermann

\section{Introduction}

Kidney stone disease is a common urological disease that poses a significant health care burden ${ }^{1}$. Calcium phosphate $(\mathrm{CaP})$ wrapped/coated with calcium oxalate $(\mathrm{CaOx})$ crystals account for approximately $70 \%$ of kidney stones, which are often associated with hypercalciuria and/or hyperoxaluria ${ }^{2}$. As the $\mathrm{CaOx}$ is slightly soluble, increases in urinary $\mathrm{Ca}^{2+}$ and/or oxalate concentrations under some selective conditions, may lead to increase the intrarenal $\mathrm{CaP}-\mathrm{CaOx}$ crystals deposition on the renal

\section{(c) The Author(s) 2019}

(c) (i) Open Access This article is licensed under a Creative Commons Attribution 4.0 International License, which permits use, sharing, adaptation, distribution and reproduction cc) in any medium or format, as long as you give appropriate credit to the original author(s) and the source, provide a link to the Creative Commons license, and indicate if changes were made. The images or other third party material in this article are included in the article's Creative Commons license, unless indicated otherwise in a credit line to the material. If material is not included in the article's Creative Commons license and your intended use is not permitted by statutory regulation or exceeds the permitted use, you will need to obtain permission directly from the copyright holder. To view a copy of this license, visit http://creativecommons.org/licenses/by/4.0/. 
parenchyma $^{3-5}$, a key phenotype seen in hyperoxaluriarelated kidney stone diseases.

Several in vitro ${ }^{4-6}$ and in vivo ${ }^{7}$ studies indicated that the $\mathrm{CaOx}$ crystals deposition and subsequent elimination could be altered by infiltrating macrophages, which are functionally classified into two types, pro-inflammatory M1 and anti-inflammatory M2 macrophages. M2 macrophages can directly suppress $\mathrm{CaOx}$ crystals deposition by phagocytizing crystals, whereas M1 macrophages may promote $\mathrm{CaOx}$ crystals deposition through altering the inflammation-related oxidative stress ${ }^{5,8}$.

Males have a higher kidney stone incidence compared with females, indicating that sex hormones may function through their receptors to influence kidney stone disease $^{9-11}$. Early studies indicated that the expression of the androgen receptor (AR) was higher in male patients with kidney stone disease ${ }^{12,13}$, and Liang et al. ${ }^{12}$ also found AR signaling could promote $\mathrm{CaOx}$ crystals deposition via increasing liver oxalate biosynthesis and renal oxidative stress. The impact of AR signaling through altering the infiltrating macrophages to influence the intrarenal $\mathrm{CaOx}$ crystals deposition and elimination, however, remains unclear.

Here we used in vitro assays plus the in vivo mouse and rat model to demonstrate that targeting $A R$ in renal tubular cells could promote the M2 macrophages recruitment/polarization to increase their phagocytic ability to decrease/eliminate the $\mathrm{CaOx}$ crystals deposition.

\section{Results}

Targeting AR in renal tubular epithelial cells increased the recruitment of macrophages

As recent studies indicate that macrophages may alter the intrarenal $\mathrm{CaOx}$ crystals elimination ${ }^{14}$, we were interested in testing the impact of the $\mathrm{AR}$ on the recruitment of macrophages to renal epithelial cells. We knocked-down AR with AR-shRNA in renal epithelial HK-2 cells and examined the impact on the phorbol 12myristate 13-acetate (PMA)-induced THP-1 macrophages (M0-MФs) recruitment to the renal epithelial HK-2 cells (see outline in Fig. 1a). The results revealed that knocking down AR increased the HK-2 cells conditioned media (CM) capacity to better recruit the M0-MФs using the transwell migration system (Fig. 1b). Similar results were observed when we replaced the HK-2 cells with another renal epithelial cell line, HKC-8 (Fig. 1b), as well as replaced the THP-1 macrophages/HK-2 cells with mouse RAW264.7 macrophages/cortical collecting duct M1 cells (Supplementary Fig. 1A-B). Importantly, we also obtained similar results when we used another AR-shRNA to knockdown AR (Supplementary Fig. 2A-C). Conversely, adding 1 or $10 \mathrm{nM}$ dihydrotestosterone (DHT) in HK-2 and HKc-8 cells resulted in decreased CM capacity to recruit the M0-MФs (Fig. 1c).

\section{Targeting AR in RTCs promoted the infiltrated macrophage M2 polarization}

To further study if targeting AR in renal epithelial cells can also influence the polarization of M0-МФs into either inflammatory macrophages (named as M1-MФs) or antiinflammatory macrophages (named as M2-MФs), we assayed the CM from renal epithelial cells with or without knockeddown AR for the impact on macrophage polarization.

As shown in Fig. 1d, we found knocking down AR in renal epithelial cells increased the polarization of M0-MФs to M2-MФs, with little influence on the M0-MФs to M1MФs. Similar results were also observed when we replaced the THP-1 macrophages/HK-2 cells with RAW264.7 macrophages/M1 cells (Supplementary Fig. 1C). Results from flow cytometry also showed that M0-MФs cultured in CM from renal epithelial cells with knocked-down AR had a higher percentage of M2-MФs expressing CD163 and CD206 than the control cells (Fig. 1e), and adding 1 or $10 \mathrm{nM}$ DHT in renal epithelial cells decreased the polarization of M0-MФs to M2-MФs (Fig. 1f).

Together, results from Fig. 1a-f and Supplementary Fig. $1 \mathrm{~A}-\mathrm{C}$ and $2 \mathrm{~A}-\mathrm{C}$, demonstrate that targeting $\mathrm{AR}$ in RTCs increased the recruitment of macrophages and polarization of recruited macrophages to the M2 type.

\section{Targeting AR in RTCs enhanced the phagocytosis of $\mathrm{CaOx}$ crystals}

To further study the impact of AR-modulated macrophages recruitment and polarization on the $\mathrm{CaOx}$ monohydrate (COM) crystals deposition, we then assayed the AR-mediated phagocytic ability of MФs. As shown in Fig. 1g-h, MФs cultured in the CM from renal epithelial cells with knocked-down AR had a higher rate of COM crystals phagocytosis than the control cells. Similar results were also observed when we used another AR-shRNA (Supplementary Fig. 2D), as well as replaced the THP-1 macrophages/HK-2 cells with RAW264.7 macrophages/ M1 cells (Supplementary Fig. 1D). Conversely, MФs cultured in the CM from renal epithelial cells treated with 1 or $10 \mathrm{nM}$ DHT had a lower rate of COM crystals phagocytosis than the control cells (Fig. 1i).

Together, results from Fig. 1a-i and Supplementary Fig. 1A-D and 2A-D suggest that knocking down AR in renal epithelial cells increase M0-MФs recruitment and promote the polarization of macrophages from M0-MФs to M2-MФs, which may then increase the ability of MФs in phagocytosis of COM crystals.

\section{Mechanism dissection of how AR can alter the MФs recruitment and M2-MФs polarization: via up-regulating the macrophage colony-stimulating factor 1 (CSF-1) expression}

To dissect the mechanisms of how targeting AR in renal epithelial cells can promote the MФs recruitment and M2 


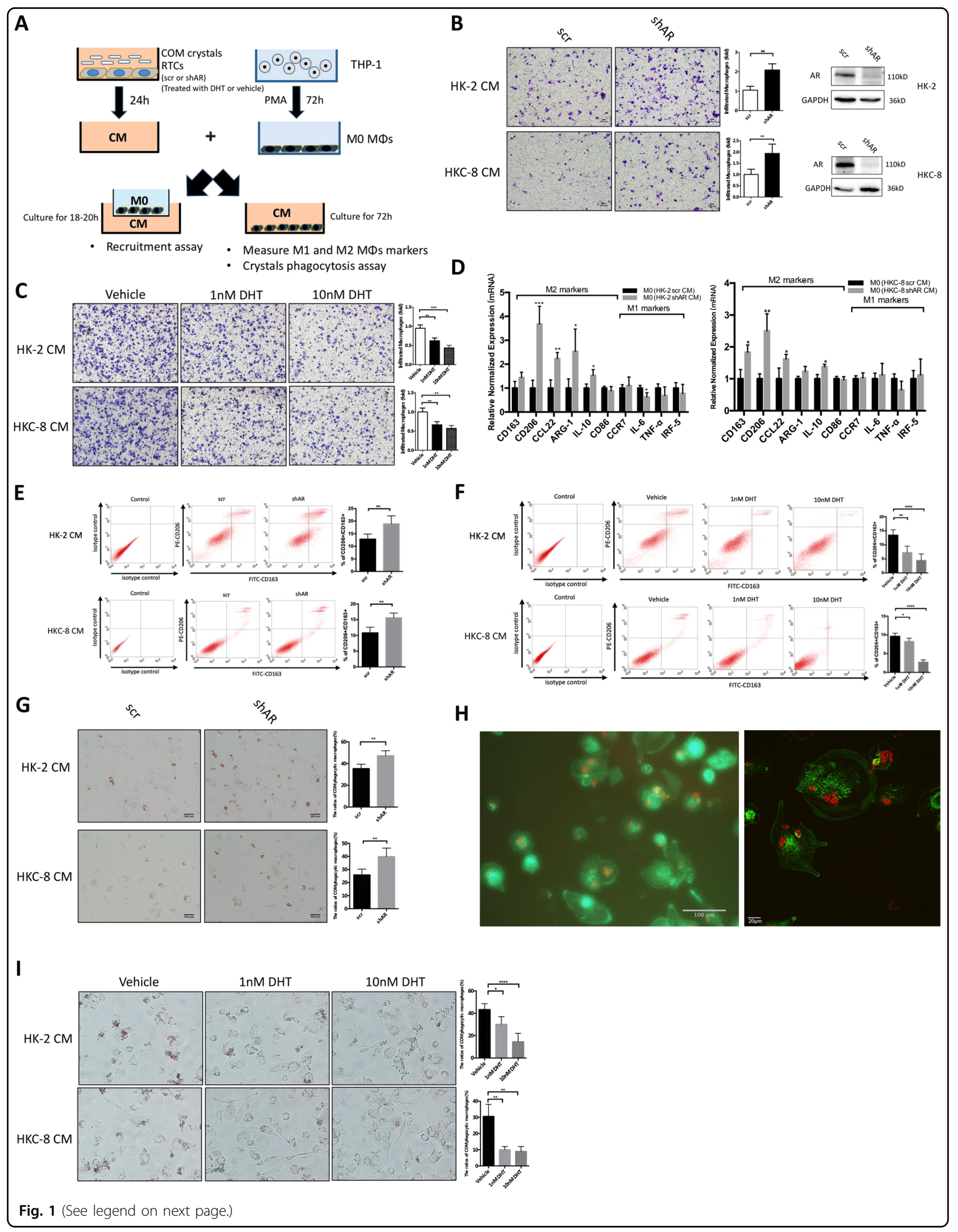




\begin{abstract}
(see figure on previous page)
Fig. 1 Targeting androgen receptor (AR) with shRNA in renal tubular epithelial cells (RTCs) increased the recruitment of macrophages, promoted macrophages M2 polarization, and increased calcium oxalate monohydrate (COM) crystals phagocytic ability of macrophages. a Expeimental outline for macrophage migration assay and crystals phagocytosis assay. Human THP-1 cells were differentiated into unpolarized macrophages (MO-MФs) by incubation with $100 \mathrm{ng} / \mathrm{ml}$ PMA for $72 \mathrm{~h}$. The conditioned media (CM) were collected from RTCs-scr/shAR (HK-2 or HKC-8 cells) treated with $20 \mu \mathrm{g} / \mathrm{cm}^{2}$ COM for $24 \mathrm{~h}$, or RTCs treated with varying concentration of DHT and $20 \mu \mathrm{g} / \mathrm{cm}^{2}$ COM for $24 \mathrm{~h}$. For macrophage migration (recruitment) assay, $1 \times 10^{5} /$ well MO-MФs were added in the upper chambers, and the CM were placed into the lower chambers of transwell plates. For M1 and M2 markers and crystals phagocytosis assay, the M0-MФs were incubated in CM that was diluted with $10 \%$ heatinactivated serum RPMI media at 1:1 for 3 days. b Macrophage migration to the RTCs CM. The M0-MDs migration to the RTCs HK-2 (scramble/shAR) CM and to the HKC-8 (scramble/shAR) CM were shown. Western blot right panels show AR knockdown efficiency. $\mathbf{c}$ Macrophage migration to the CM from RTCs treated with varying concentration of DHT and $20 \mu \mathrm{g} / \mathrm{cm}^{2}$ COM. d CM from AR-depleted RTCs showed increased mRNA levels of markers of M2 phenotypic MФs, including CD163, CD206, CCL22, Arg-1, and IL-10 in MO-MØs after $72 \mathrm{~h}$ of incubation compared with CM from control (scramble) RTCs by quantitative real-time PCR (qRT-PCR). e Representative flow cytometry analysis of CD163 and CD206 expression in M0-MФs after $72 \mathrm{~h}$ of incubation in CM from AR-depleted or control RTCs. f Representative flow cytometry analysis of CD163 and CD206 expression in M0-MФs after $72 \mathrm{~h}$ of incubation in CM from RTCs treated with varying concentration of DHT. $\mathbf{g}$ Analysis of the COM crystals phagocytosis ability of MФs after incubation with HK-2 (scramble/shAR) CM or HKC-8 (scramble/shAR) CM for $72 \mathrm{~h}$. After 3 days incubation with CMs, the MФs were treated with $15 \mu \mathrm{g} /$ $\mathrm{cm}^{2}$ Ponceau-S-stained COM crystals. At $24 \mathrm{~h}$, the crystals MФs uptake was evaluated by optical microscopy. Representative images are shown (left panel). Quantification at right shows mean \pm SD percent of MФs containing phagocytized red material (right panel). $\mathbf{h}$ Fluorescence micrograph (left panel) and confocal laser scanning micrograph (right panel) of PMA-differentiated THP-1 MФs phagocytosed COM crystals. The MФs were stained by Cytopainter Phalloidin-iFlour 488 (green), and the COM crystals were stained by Ponceau-S (red). i Analysis of the COM crystals phagocytosis ability of MФs after incubation for $72 \mathrm{~h}$ with CM from RTCs treated with varying concentration of DHT. For $\mathbf{b}, \mathbf{c}, \mathbf{e}, \mathbf{f}, \mathbf{g}$, and $\mathbf{i}$ quantifications are at the right. All quantitations are presented as mean $\pm \mathrm{SD},{ }^{*} P<0.05,{ }^{* *} P<0.01,{ }^{* * *} P<0.001,{ }^{* * *} P<0.0001$ by Student's $t$-test $(\mathbf{b}, \mathbf{e}, \mathbf{g})$ or One-way ANOVA followed by Bonferroni multiple comparison test $(\mathbf{c}, \mathbf{f}, \mathbf{i})$
\end{abstract}

polarization, we first screened commonly known cytokines related to MФs recruitment and M2 polarization $^{15-18}$. The results revealed that the expression of mRNA from some selective cytokines, including CSF-1, interleukin-10 (IL-10), and IL-34, were altered after manipulating the AR expression (Fig. 2a). Among these cytokines, we noticed that the CSF-1 mRNA expression was altered most significantly. Importantly, we also confirmed the CSF-1 protein expression of renal epithelial cells was also increased after knocking down AR (Fig. 2b, c), and when we replaced the THP-1 macrophages/HK-2 cells with RAW264.7 macrophages/M1 cells (Supplementary Fig 1. E-F). We therefore decided to further study the impact of CSF-1 on the AR-altered MФs recruitment and M2 polarization.

Using an interruption approach, we confirmed that knocking down CSF-1 with shRNA could partially reverse the AR knockdown-increased M0-MФs recruitment (Fig. 2d, e), and M2 polarization (Fig. 2f, g), suggesting that targeting AR in renal epithelial cells may function via increasing the CSF-1 expression in the CM to promote MФs recruitment and M2 polarization. Importantly, the results from COM phagocytosis assay also supported that targeting AR in renal epithelial cells could enhance the MФs COM crystals phagocytic ability and is CSF-1 dependent (Fig. 2h). Similar results were also obtained when we used the second CSF-1-shRNA (Supplementary Fig, 2E-F), as well as when we replaced the THP-1 macrophages/HK-2 cells with RAW264.7 macrophages/ M1 cells (Supplementary Fig. 1G-I).

Together, results from Figs. $2 \mathrm{a}-\mathrm{h}$ and Supplementary Fig. 1E-I and 2E-F suggest that targeting AR in renal epithelial cells may function via upregulating the CSF-1 signals to enhance the MФs recruitment and M2 polarization.

\section{Mechanism dissection of how AR suppresses CSF-1 protein expression: via upregulating the miR-185-5p expression}

To dissect the detailed mechanism(s) how knocking down AR can increase the CSF-1 protein expression, we focused on miRNA regulation as we failed to identify a potential androgen response element (ARE) on the CSF-1 promoter region that could be validated by the chromatin immunoprecipitation (ChIP) in vivo binding assay (data not shown). We then selected 18 miRNAs that might be able to target CSF-1 via binding to the $3^{\prime}$ untranslated region (3'-UTR) from analysis results of databases (Targetscan, miRanda, RNA22, and miRWalk) and applied quantitative real-time PCR (qRT-PCR) to determine whether any of these potential miRNA candidates might be the targets after knocking down AR in renal epithelial cells. The results revealed that, in cells incubated with $20 \mu \mathrm{g} / \mathrm{cm}^{2}$ COM crystals, the expressions of five miRNAs (miR-15a-5p, miR-130b-3p, miR-185-5p, miR-650, and miR-1207-5p) were significantly suppressed after knocking down AR in HK-2 and HKC-8 cells (Fig. 3a, b).

We further assayed the consequences on CSF-1 expression after adding these five miRNAs to the HK-2 and HKC8 cells, and results suggest that miR-185-5p is the best candidate for further study since altering this miRNA significantly decreased CSF-1 expression (Fig. 3c, d).

As expected, results from the interruption approach via adding miR-185-5p led to partially reverse AR-shRNAenhanced CSF-1 expression in HK-2 and HKC-8 cells (Fig. 3e, f). The consequences of such reversion may then lead to partially reverse the targeted AR-enhanced 


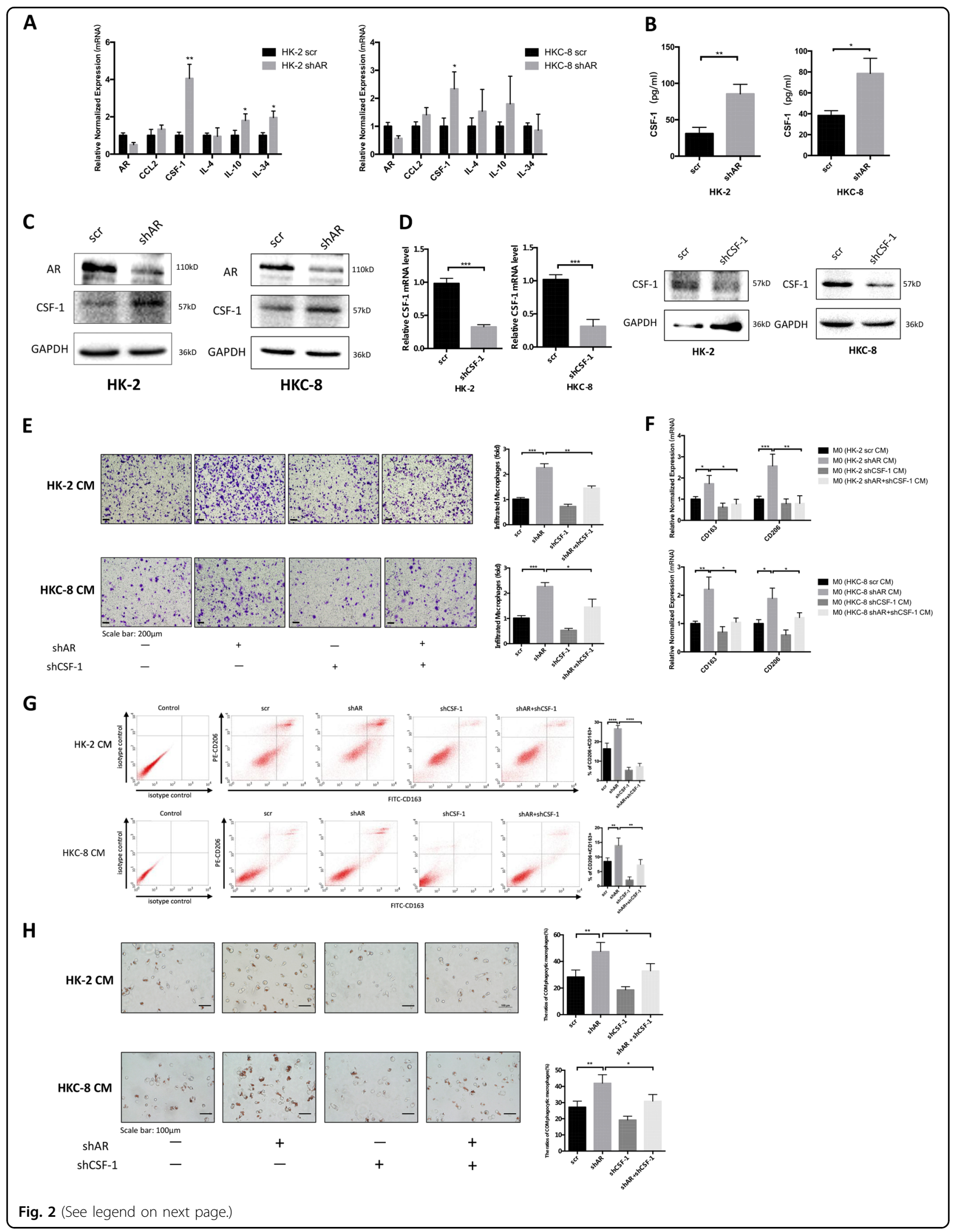


(see figure on previous page)

Fig. 2 Knocking down androgen receptor (AR) in renal tubular epithelial cells (RTCs) enhanced the macrophages migration and M2 polarization via modulating the CSF-1 signals. a-c Cells were pre-treated with shAR or with scrambled control (scr). After $72-\mathrm{h}$ incubation, cells were treated with $20 \mathrm{\mu g} / \mathrm{cm}^{2}$ COM crystals for $24 \mathrm{~h}$. a Quantitative real-time PCR (qRT-PCR) analysis of MФs-associated cytokines in HK-2 and HKC-8 cells with/without knockdown of AR. $\mathbf{b}$ The level of CSF-1 in the CM of RTCS was detected by ELISA. $\mathbf{c}$ The level of CSF-1 in the RTCS lysates was detected by western blot. d qRT-PCR (left panels) and western blot (right panels) show CSF-1 knockdown efficiency in HK-2 and HKC-8 cells. e Knocking down AR in HK-2 and HKC-8 cells increased MO-MФs migration, whereas knocking down CSF-1 interrupted the AR knockdown-mediated increase of MO-MФs migration. $\mathbf{f}$ CM from AR-depleted RTCs led to increase mRNA levels of markers of M2 phenotypic MФs (CD163 and CD206), whereas knocking down CSF-1 in RTCs interrupted AR knockdown-mediated M2-MФs markers change. $\mathbf{g}$ Flow cytometry analysis showed that CM from AR-depleted RTCS led to increase expressions markers of M2 phenotypic MФs (CD163 and CD206), whereas knocking down CSF-1 in RTCS interrupted AR knockdown-mediated M2-MФs markers change. $\mathbf{h}$ Knocking down CSF-1 in HK-2 and HKC-8 partly reversed the AR knockdownenhanced COM crystals phagocytic ability of MФs. For $\mathbf{e}, \mathbf{g}$ and $\mathbf{h}$, quantifications are at the right. All quantitations are presented as mean $\pm S D$. ${ }^{*} P<$ $0.05,{ }^{* *} P<0.01,{ }^{* * *} P<0.001,{ }^{* * *} P<0.0001$

M0-MФs recruitment and COM crystals phagocytic ability of MФs (Fig. 3g, h). Similar results were also observed when we replaced the THP-1 macrophages/HK2 cells with RAW264.7 macrophages/M1 cells (Supplementary Fig. 1J-N).

Together, results from Fig. 3a-h and Supplementary Fig. 1J-N, using multiple macrophages and renal epithelial cells, suggest AR can suppress CSF-1 protein expression via upregulating the miR-185-5p expression in the renal epithelial cells.

\section{Mechanism dissection of how AR increases miR-185-5p expression}

To further dissect the molecular mechanism how AR can upregulate miR-185-5p expression in the renal epithelial cells exposed to COM crystals, we searched for potential AREs on the $2 \mathrm{~kb} 5^{\prime}$ promoter region of miR185-5p using the JASPAR database. The results identified five putative AREs located within the miR-185-5p promoter region (Fig. 4a), and results from the ChIP assay revealed that AR could bind to the ARE located at 1461-1475-bp upstream of the transcriptional start site of miR-185-5p in HK-2 cells (Fig. 4b). Furthermore, using the luciferase assay to examine the $1.7 \mathrm{~kb}$ miR-185-5p promoter region that was linked to the pGL3-basic Vector (Promega), we found that knocking down AR with ARshRNA could decrease the luciferase expression of the miR-185-5p wild-type (WT) promoter construct, but not the ARE mutant promoter construct, in HK-2 cells exposed to COM crystals (Fig. 4c).

Together, results from Fig. $4 \mathrm{a}-\mathrm{c}$ suggest AR can upregulate miR-185-5p expression via transcriptional regulation with binding to ARE on its $5^{\prime}$ promoter in the renal epithelial cells.

\section{Mechanism dissection of how AR increased miRNA-185-5p led to suppressing the CSF-1 expression}

To dissect the mechanism how AR increased miR-185$5 \mathrm{p}$ can suppress the CSF-1 expression, we searched for the potential binding sites of miR-185-5p located on the 3'-
UTR of CSF-1 mRNA, and identified two predicted miRNA-responsive-elements that matched the seed sequence of miR-185-5p in the 3'-UTR of CSF-1 gene (Fig. 4d). We then inserted a 1705-bp fragment from the CSF-1 3'-UTR with the predicted miR-185-5p target sites into a dual-luciferase reporter backbone psiCHECK ${ }^{\mathrm{TM}}-2$ downstream of the Renilla luciferase open reading frame, as well as a mutated version at the predicted target sites (Fig. $4 \mathrm{~d}$, left). The luciferase assay results revealed that miR-185-5p could suppress luciferase expression of the WT CSF-1 3'-UTR construct, the mutant 1 and mutant 2 CSF-1 3'-UTR constructs, but not the mutant $1+2$ CSF-1 3'-UTR construct, suggesting that miR-185-5p could directly target the CSF-1 3'-UTR to decrease its expression (Fig. 4d, right).

\section{In vivo study using mouse model to determine the AR role in the development of $\mathrm{CaOx}$ crystals deposition}

To confirm the above in vitro cell line results with the in vivo mouse model, we generated renal tubule-specific AR knockout mice (Cdh16-ARKO) by breeding floxed AR mice with Cdh16 promoter-driven Cre transgenic mice, in which Cre expression is limited to the renal tubules, including Bowman's capsule, proximal tubules, and loop of Henlé and distal tubules ${ }^{19}$ (Fig. 5a). Genotyping results show that Cdh16-ARKO mice had both Cre and floxed AR alleles (Fig. 5b). To verify the loss of AR in renal tubules of Cdh16-ARKO mice at the protein level, we performed immunohistochemical (IHC) analysis and demonstrated that the AR-positive renal epithelial cells were drastically reduced in Cdh16-ARKO mice in comparison with WT mice (Fig. 5c).

We then utilized i.p. injections of glyoxylate to induce renal $\mathrm{CaOx}$ crystals deposition to investigate the renal tubular AR effect on the $\mathrm{CaOx}$ crystals deposition. Male mice were given daily i.p. injections of glyoxylate $(80 \mathrm{mg} /$ $\mathrm{kg} /$ day). Six days after glyoxylate injections, the mice were euthanized to determine the $\mathrm{CaOx}$ crystals deposition. As shown in Fig. 5d, e, Cdh16-ARKO mice had fewer $\mathrm{CaOx}$ crystals deposition than the WT mice. 


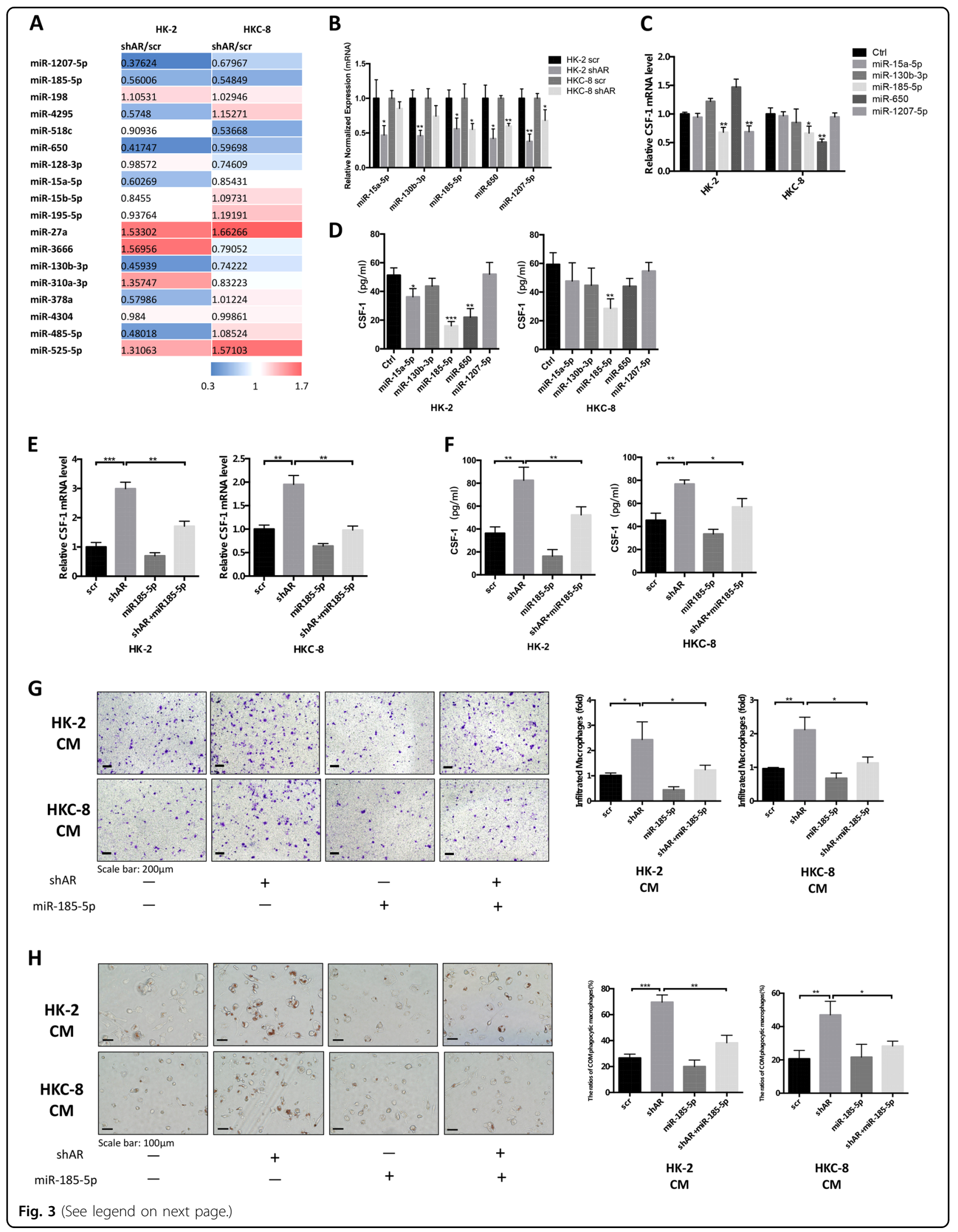


(see figure on previous page)

Fig. 3 Androgen receptor (AR) modulates CSF-1 via upregulation of miR-185-5p in renal tubular epithelial cells (RTCs) exposed to calcium oxalate monohydrate (COM) crystals. a Eighteen potential miRNAs candidates were screened by quantitative real-time PCR (qRT-PCR) assay in HK-2 cells and HKC-8 cells based on their response to knocking down AR. Cells were pre-treated with $20 \mu \mathrm{g} / \mathrm{cm}^{2}$ COM crystals for $24 \mathrm{~h}$. $\mathbf{b}$ The qRT-PCR analysis of five miRNAs in both HK-2 and HKC-8 cells with shAR compared with control. $\mathbf{c}, \mathbf{d}$ HK-2 and HKC-8 cells were virally transduced with miR15a-5p, miR-130b-3p, miR-185-5p, miR-650, and miR-1207-5p. Cells were then exposed to $20 \mu \mathrm{g} / \mathrm{cm}^{2}$ COM crystals for $24 \mathrm{~h}$. Total RNAs (c) were analyzed for CSF-1 by qRT-PCR. The protein expression levels (d) of CSF-1 in the CM of HK-2 and HKC-8 cells were assessed by ELISA. e The mRNA levels of CSF-1 were determined by qRT-PCR analysis after co-transfection with shAR and miR-185-5p (vs. scramble). $\mathbf{f}$ The protein levels of CSF-1 in RTCS CM were determined by ELISA after co-transfection with shAR and miR-185-5p (vs. scramble). $\mathbf{g}$ M0-MФs migration to the CM from HK-2 cells (upper) and HKC-8 cells (lower) with four groups (scramble, shAR, miR-185-5p, and shAR + miR-185-5p). $\mathbf{h}$ Overexpressing miR-185-5p in HK-2 cells and HKC-8 cells partly reversed the AR knockdown-enhanced COM crystals phagocytic ability of MФs. For $\mathbf{g}$ and $\mathbf{h}$, quantifications are at the right. All quantitations are presented as mean $\pm \mathrm{SD}$. ${ }^{*} P<0.05,{ }^{* *} P<0.01,{ }^{* *} P<0.001$

We next examined the effect of targeting AR on renal function and histologic changes in the mice after inducing the $\mathrm{CaOx}$ crystals deposition. The results revealed that Cdh16-ARKO mice have a decrease in serum creatinine as compared with the WT mice (Fig. 5f). In addition, deleterious tissue changes in the medulla (tubular necrosis and casts formation) by periodic acid-Schiff (PAS) staining were staining were more evident in kidneys from WT mice than in kidneys from Cdh16-ARKO mice (Fig. 5g).

We further evaluated renal fibrosis by IHC staining of aSMA, and results indicated that kidneys from Cdh16ARKO mice exhibited a decreased number of myofibroblasts, compared with kidneys from WT mice (Fig. 5h).

Together, these results from Fig. 5a-h suggest that targeting the renal epithelial AR may lead to reduction of glyoxylate-induced renal $\mathrm{CaOx}$ crystals deposition.

Increased CSF-1 expression and M2-polarized MФs in the Cdh16-ARKO mouse with glyoxylate-induced $\mathrm{CaOx}$ crystals deposition

We then assayed the CSF-1 mRNA and miR-185-5p expression in kidney tissues via qRT-PCR assay, and the results showed that a higher renal CSF-1 mRNA and a lower miR-185-5p expression were detected in Cdh16ARKO mice compared with WT mice after glyoxylate treatment (Fig. 6a). Importantly, results from IHC, enzyme-linked immunosorbent assay (ELISA), and microRNA in situ hybridization (MISH) assay also showed higher CSF-1 protein expression (Figs. 6b, c) and lower miR-185-5p expression (Fig. 6d) in Cdh16-ARKO mice.

We next assayed the recruitment of macrophages in renal tissues, and found Cdh16-ARKO mice had higher renal expression of F4/80 (a widely used marker of murine macrophages ${ }^{20}$ ) vs. WT mice at the mRNA level (Fig. 6e) and at the protein level (Fig. 6f).

We then examined the population of M1-MФs vs. M2MФs in the renal tissues, and showed that the renal mRNA expressions of M2-MФs markers, including the CD163 and CD206, were significantly higher in Cdh16-ARKO mice as compared with those found in WT mice (Fig. 6e). In contrast, the renal mRNA expression of iNOS, a M1-MФs marker, was not significantly different between Cdh16ARKO and WT mice (Fig. 6e). Importantly, IHC and immunofluorescence staining further confirmed these differences at the protein level (CD163 in Fig. 6g and CD206 in Fig. 6h) in Cdh16-ARKO vs WT mice.

Together, results from Fig. 6a-h suggest that Cdh16ARKO mice have reduced $\mathrm{CaOx}$ crystals deposition with increased M2 macrophage recruitment.

In vivo study using ASC-J9 ${ }^{\circledR}$ to degrade AR in the hydroxyL-proline (HLP)-induced $\mathrm{CaOx}$ crystals deposition rat model led to the reduction of $\mathrm{CaOx}$ crystals deposition

All in vivo studies using the ARKO mouse model (Figs. 5, 6) demonstrated that AR induced $\mathrm{CaOx}$ crystals deposition via altering the renal M2 macrophages recruitment/polarization. This mouse model demonstrated how AR may impact the development of intrarenal $\mathrm{CaOx}$ crystals deposition in vivo ${ }^{21}$. To substantiate these results in another animal model, we used rats fed with HLP for 8 weeks to induce intrarenal $\mathrm{CaOx}$ crystals deposition $^{22}$, as recent studies indicated this rat fed with HLP more closely modeled human intrarenal $\mathrm{CaOx}$ crystals deposition without inducing the acute kidney injury $^{21,22}$.

We also replaced the knockout AR strategy by treating with the small molecule, ASC-J $9^{\circledR}$, which can selectively degrade $\mathrm{AR}^{23-28}$ in this second animal model. We first fed rats with chow mixed with 5\% HLP (weight/weight, HLP/ chow) for 8 weeks. After 4 weeks' administration of HLP, rats were i.p. injected with ASC-J $9^{\circledR}(37.5 \mathrm{mg} / \mathrm{kg} / 48 \mathrm{~h})$, or control vehicle (N,N-dimethylacetamide, DMA), and AgomiR-185-5p or AgomiR-negative control (NC) (15 nmol/kg/week) for 4 weeks (see details in Fig. 7a). The results revealed that ASC- $\mathrm{J} 9^{\circledR}$ could degrade AR in kidney as compared with control mice that received vehicle (Fig. 7b). Importantly, using Pizzolato staining to examine the $\mathrm{CaOx}$ crystals deposition in rat kidney, we found fewer $\mathrm{CaOx}$ crystals deposition in the ASC- $59^{\circledR}$-treated rats than those in the vehicle control-treated rats. 


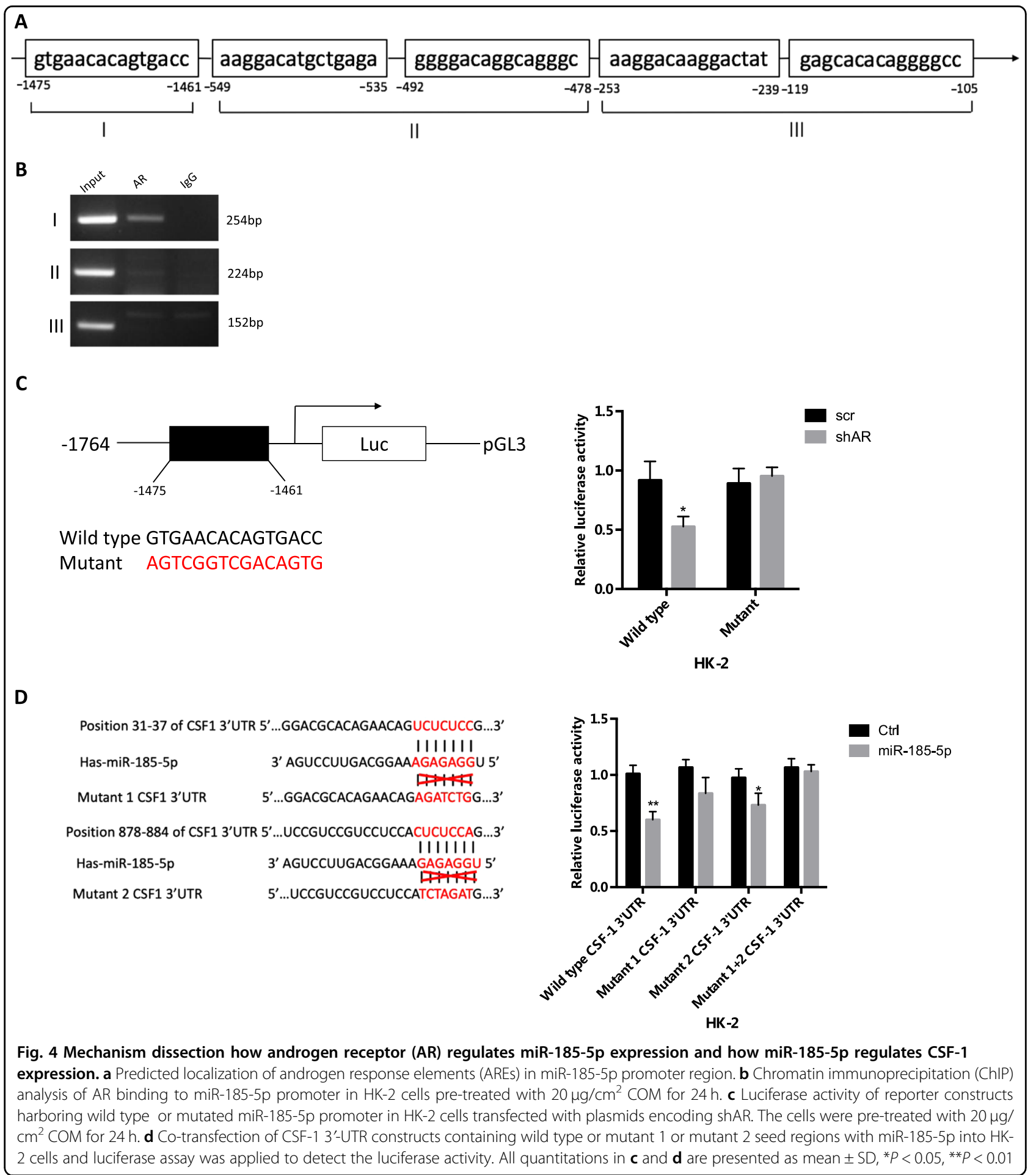

As expected, results from an interruption approach via adding miR-185-5p can then partially reverse/block the ASC-J ${ }^{\circledR}{ }^{-}$-reduced $\mathrm{CaOx}$ crystals deposition (Fig. 7c).

Results from qRT-PCR assay also revealed a higher renal CSF-1 mRNA expression in the ASC- $59^{\circledR}$-treated rats compared with control rats (Fig. 7d), and IHC staining also showed higher CSF-1 protein expressions in the $\mathrm{ASC}-\mathrm{J} 9^{\circledR}$ treated rats (Fig. 7e). Adding miR-185-5p led to reverse the effect of ASC-J9-enhanced CSF-1 expression.

We next assayed the recruitment of macrophages in renal tissues, and found $\mathrm{ASC}-\mathrm{J}^{\circledR}$ treated rats had higher renal expression of CD68 (a widely used marker of rat macrophages ${ }^{20}$ ) vs. control kidneys at the mRNA level 


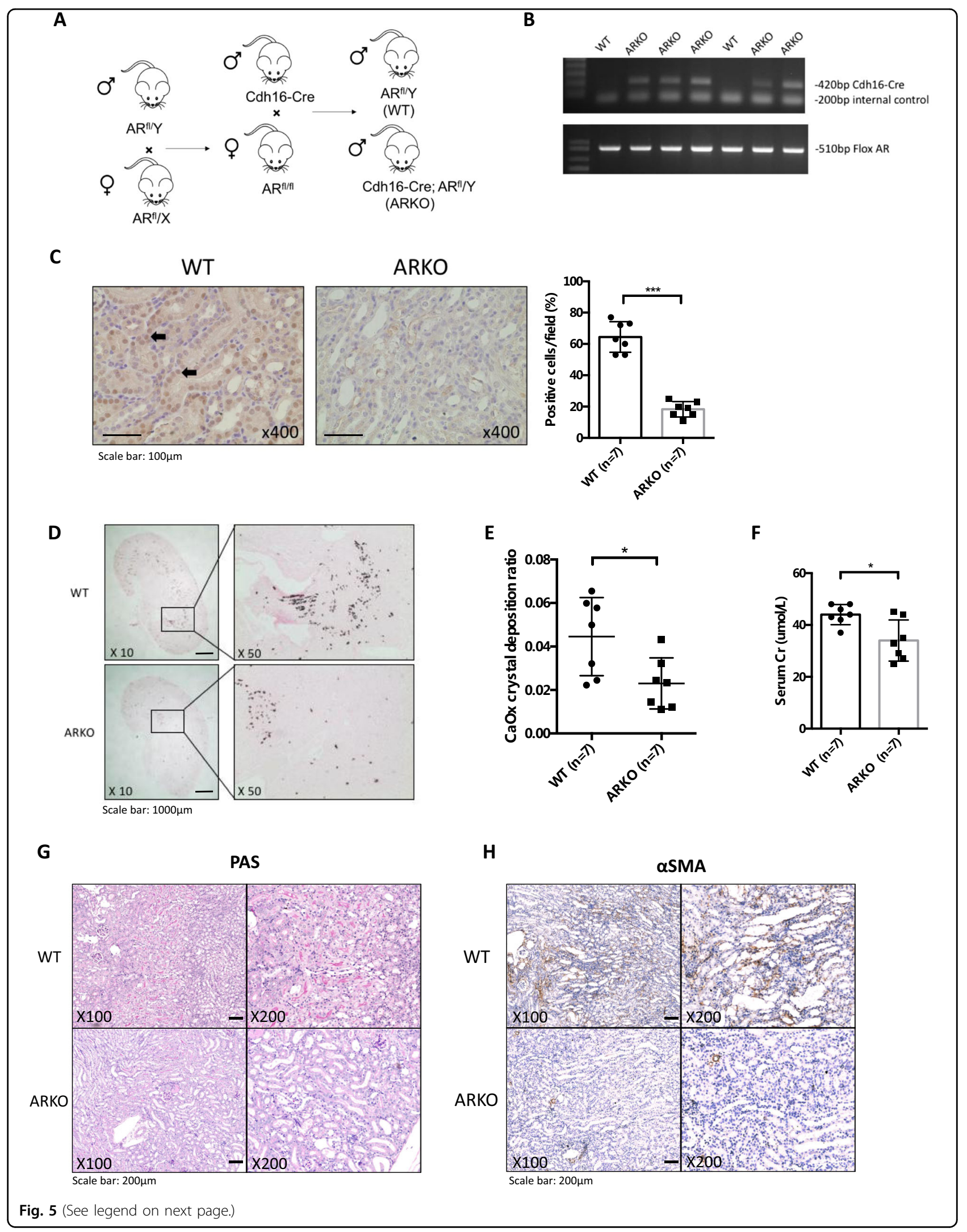


(see figure on previous page)

Fig. 5 Loss of renal tubular epithelial androgen receptor (AR) gene decreased the intrarenal calcium oxalate (CaOx) crystals deposition in glyoxylate-induced CaOx deposition mouse model. a Renal tubular epithelial ARKO mouse breeding scheme. Male mice with Cre coding sequence under the control of the mouse cadherin 16 (Cdh16) promoter were bred with female flox AR mice (AR/fl/) to generate wild type (WT, noncarrier for Cdh16-Cre) and Cdh16-Cre/ARKO mice (Cdh16-ARKO). b Tail genomic DNA was isolated for genotyping by PCR using primers flanking AR exon 2 and Cre primers. c AR protein expression (left panels) was detected in male kidneys of WT and Cdh16-ARKO mice by immunohistochemistry (IHC). Black arrows indicate cells expressing AR protein. Quantifications of AR-positive cells in the mouse renal tissues were shown at right. $\mathbf{d}$ Glyoxylate-induced intrarenal CaOx crystals deposition was compared between WT and Cdh16-ARKO male mice. e Quantitation (mean \pm SD) of intrarenal $\mathrm{CaOx}$ crystals deposition in each kidney section. Higher numbers of intrarenal $\mathrm{CaOx}$ crystals were found in the WT mice than in the Cdh16ARKO mice. f Serum creatinine ( $\mathrm{Cr}$ ) level was compared between WT and Cdh16-ARKO male mice after glyoxylate treatment. $\mathbf{g}$ Representative histologic images of periodic acid-Schiff (PAS)-stained kidney sections from WT and ARKO mice. $\mathbf{h}$ Immunostaining of a-smooth muscle actin (aSMA) in kidney sections from WT and ARKO mice. ${ }^{*} P<0.05$, ${ }^{* *} P<0.001$ compared with WT mice

(Fig. 7f) and at the protein level (Fig. 7g), and adding miR185-5p could then lead to partially reverse/block the ASC$\mathrm{J} 9^{\circledR}$-enhanced recruitment of macrophages.

Finally, we examined the expression of M1-MФs and $\mathrm{M} 2-\mathrm{M} \Phi \mathrm{s}$ in the renal tissues, and results revealed that the renal mRNA expression of M2-MФs markers was significantly higher in ASC- $\mathrm{J}^{\circledR}$ treated rats as compared with those found in control rats (Fig. 7f). In contrast, we found little difference in the renal mRNA expression of iNOS, a M1-MФs marker, between the two groups (Fig. 7f). Importantly, IHC also confirmed these differences at the protein level (CD163 in Fig. 7h and CD206 in Fig. 7i as well as iNOS in Fig. 7j) in ASC-J $9^{\circledR}$ treated rats vs. control rats. As expected, adding miR-185-5p could then lead to partially reverse/block the ASC-J $9{ }^{\circledR}$ induced M2 macrophages polarization.

Taken together, the results from in vivo study using rat model (Fig. 7a-j) demonstrate that targeting AR with ASC- $J 9^{\circledR}$ is an effective new therapeutic approach to better suppress the $\mathrm{CaOx}$ crystals deposition via altering the AR-mediated miR-185-5p/CSF-1/M2 macrophages recruitment and polarization signaling.

\section{Discussion}

The kidney is susceptible to crystals/stone formation as urine ion concentrations favor supersaturation, which promotes crystalization and crystals formation/deposition that may lead to acute kidney injury, nephrocalcinosis and chronic kidney disease ${ }^{29}$. In the present study, we found AR could alter the $\mathrm{CaOx}$ crystals deposition via suppressing the macrophages recruitment and polarization of macrophages towards the M2 phenotype (Fig. 8). These findings may provide valuable information for future potential approaches via altering the AR-meditated macrophages recruitment/polarization signals to suppress the $\mathrm{CaOx}$ crystals deposition. These results are in agreement with previous studies indicating that infiltrating $\mathrm{M} 2-\mathrm{M} \Phi \mathrm{s}$ have an important physiological role in decreasing the $\mathrm{CaOx}$ crystals deposition via engulfing the $\mathrm{CaOx}$ crystals fragments ${ }^{14}$.

The renal $\mathrm{CaOx}$ crystals deposition may start with the formation of the $\mathrm{CaP}$ nuclei in the renal interstitium that is gradually developed into the Randall plaques, and erosion of these plaques into the urinary space may then promote the heterogeneous nucleation with supersaturated $\mathrm{CaOx}$ to form the kidney stones ${ }^{30,31}$. In contrast, some kidney stone formers have their crystals initially arise within the the tubule lumens of terminal collecting ducts. Since all current available mouse and rat models for the kidney stone diseases developed few Randall plaques, their kidney crystals formation may be more close to those kidney stone patients with hyperoxaluria.

It is now well recognized that macrophages serve numerous functions and manifest a variety of phenotypes $^{32}$. Taguchi et al. ${ }^{5}$ reported that M2 macrophages might suppress $\mathrm{CaOx}$ crystals deposition in M2-deficient mice through phagocytosis of the renal $\mathrm{CaOx}$ crystals with inhibiting inflammation. In contrast, M1 macrophages are not able to remove intrarenal $\mathrm{CaOx}$ deposits and might further accelerate oxidative-induced kidney injury via promoting the renal inflammation. Here we showed that exposure of macrophages to the $\mathrm{CM}$ of renal tubular cells with AR-shRNAs could lead to increased expression of M2 markers and alter their crystals phagocytic ability in vitro. Importantly, results from two animal models also showed that targeting AR in the renal cells could decrease $\mathrm{CaOx}$ crystals deposition with increasing the M2 macrophages infiltration in the kidneys.

CSF-1 plays key roles in renal macrophages proliferation and polarization ${ }^{33}$, and is well known for its role in the bone marrow to facilitate the production of blood monocytes, the precursors for the tissue macrophages $^{34,35}$. Renal tubular cells were identified as the major site of CSF-1 production ${ }^{34,36}$. Wang et al. ${ }^{36}$ established proximal tubule production of CSF-1 as important for polarization of renal MФs and recovery from acute kidney injury. CSF-1 has also been identified as a powerful regulator for macrophages proliferation, differentiation, and polarization for suppression of $\mathrm{CaOx}$ crystals deposition $^{5,6,14,37,38}$. Sergei et al. ${ }^{6}$ demonstrated in vitro that MФs differentiated with CSF-1 were able to effectively phagocytize renal $\mathrm{CaOx}$ crystals $<200 \mu \mathrm{m}$. Taguchi 


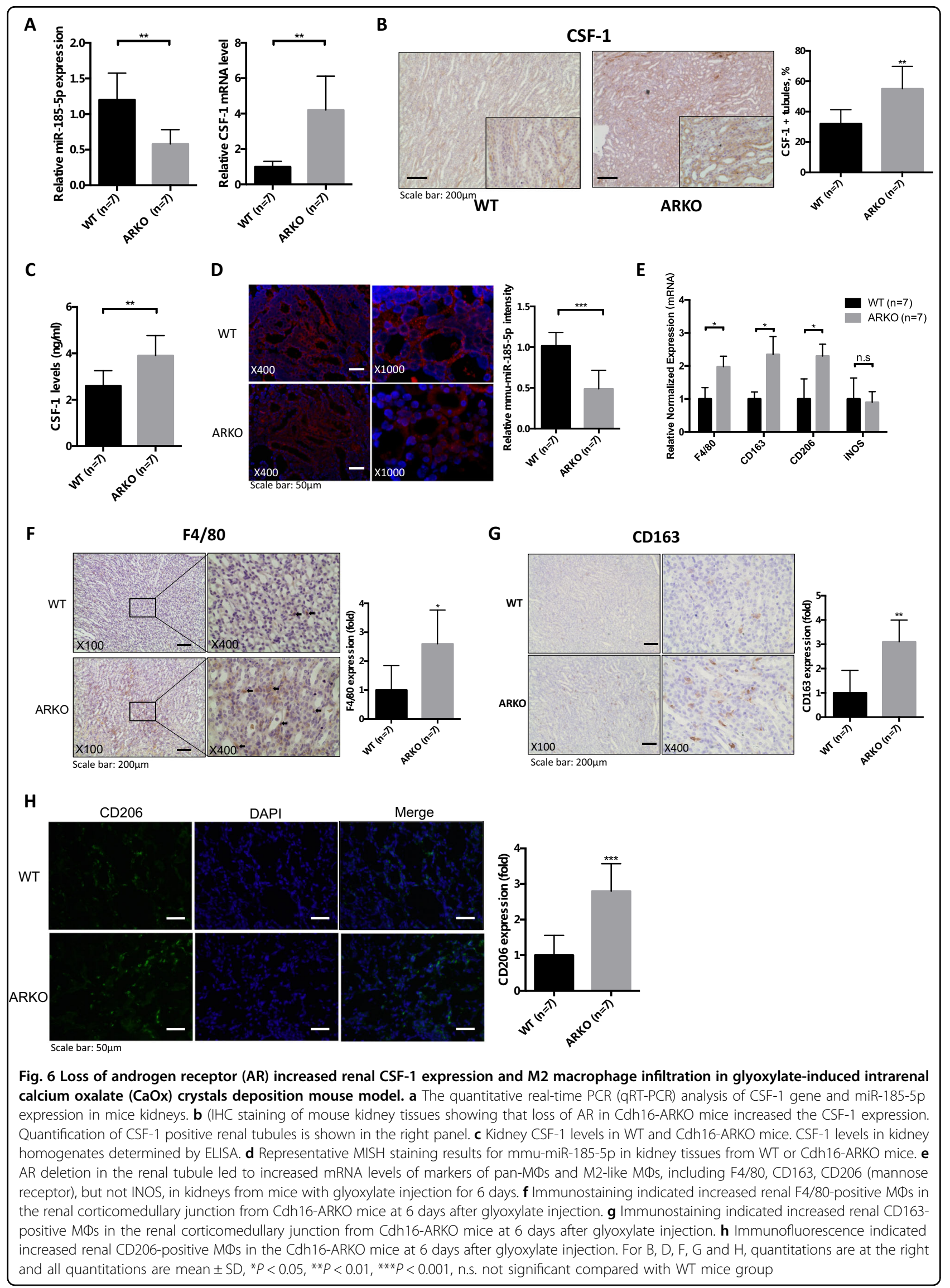




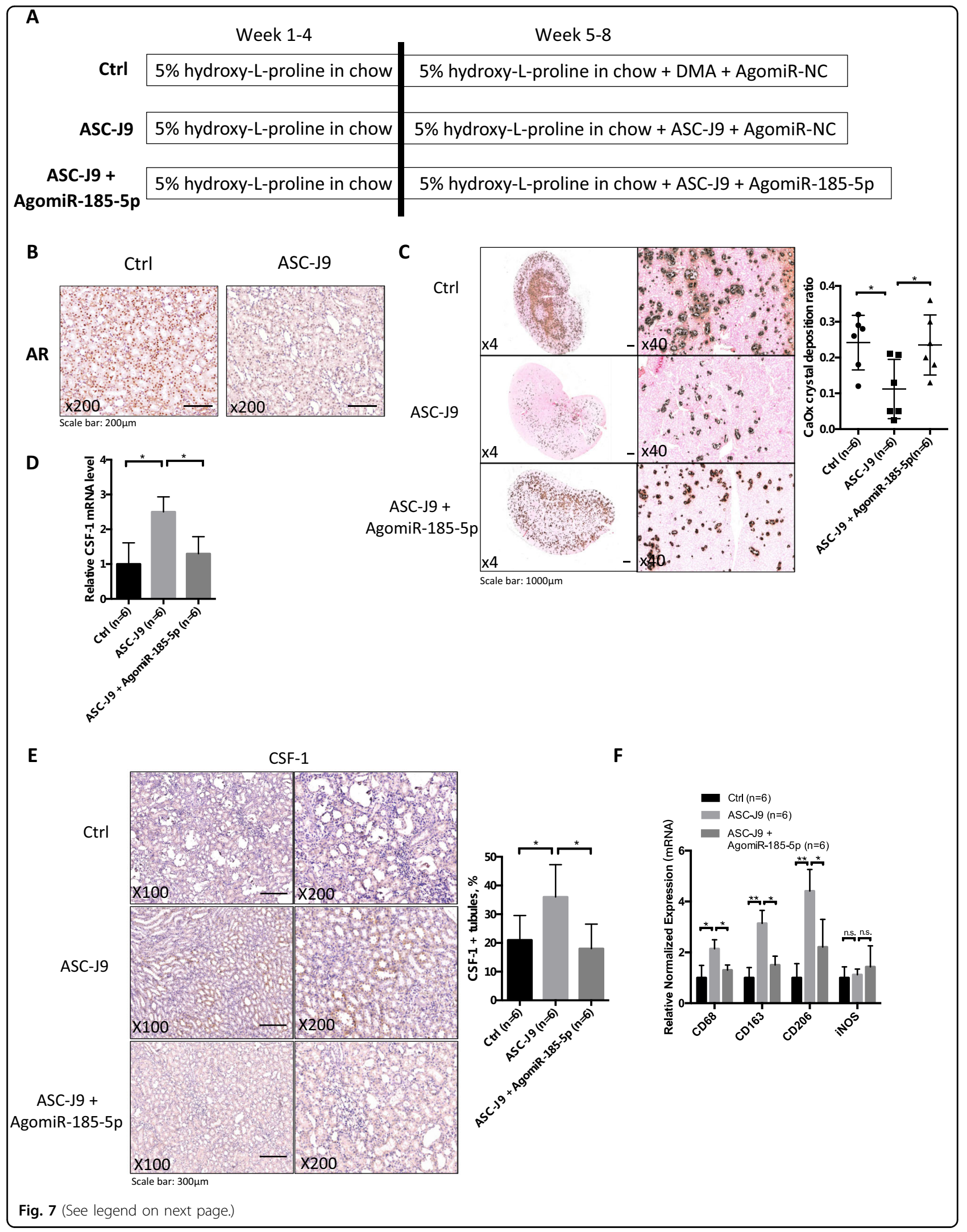




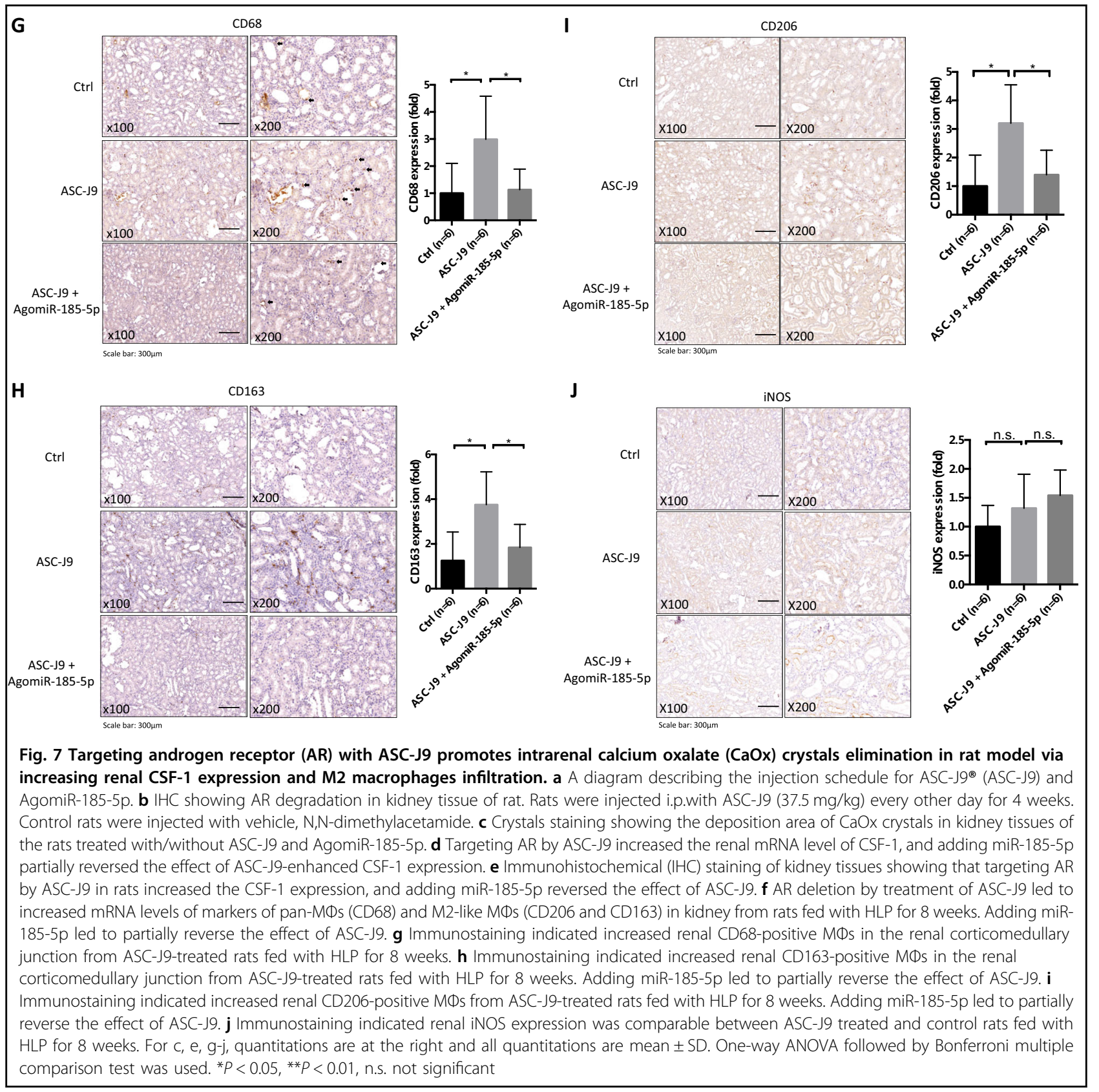

et al. ${ }^{5}$ reported that a lack of CSF-1 production in the op/ op mouse leads to a markedly increased intrarenal $\mathrm{CaOx}$ crystals deposition and substantially reduced renal M2like macrophage populations, and adding CSF-1 could then reverse such deficiency.

Here, we first confirmed that CSF-1 derived from renal tubular cells can play a key role in altering the renal macrophages and $\mathrm{CaOx}$ crystals deposition. We further proved that AR could modulate CSF-1 expression in renal epithelial cells, suggesting that it is possible to alter the CSF-1 expression via targeting AR to suppress the intrarenal $\mathrm{CaOx}$ crystals deposition.
ASC- $59^{\circledR}$ is a newly developed AR degradation enhancer that can selectively degrade AR in some cells. Recent studies have demonstrated that ASC-J9 $9^{\circledR}$ can suppress many ARmediated diseases, including prostate cancer, liver cancer, and spinal and bulbar muscular atrophy neuron disease ${ }^{25-28,39}$. Our in vivo results showing ASC-J9 ${ }^{\circledR}$ can also suppress $\mathrm{CaOx}$ crystals deposition via altering the $\mathrm{M} 2$ macrophages recruitment/polarization may provide a novel approach to suppress $\mathrm{CaOx}$ crystals deposition.

In summary, our study demonstrated that that renal tubular AR could function through altering the macrophage recruitment and $\mathrm{M} 2$ polarization to influence the $\mathrm{CaOx}$ 


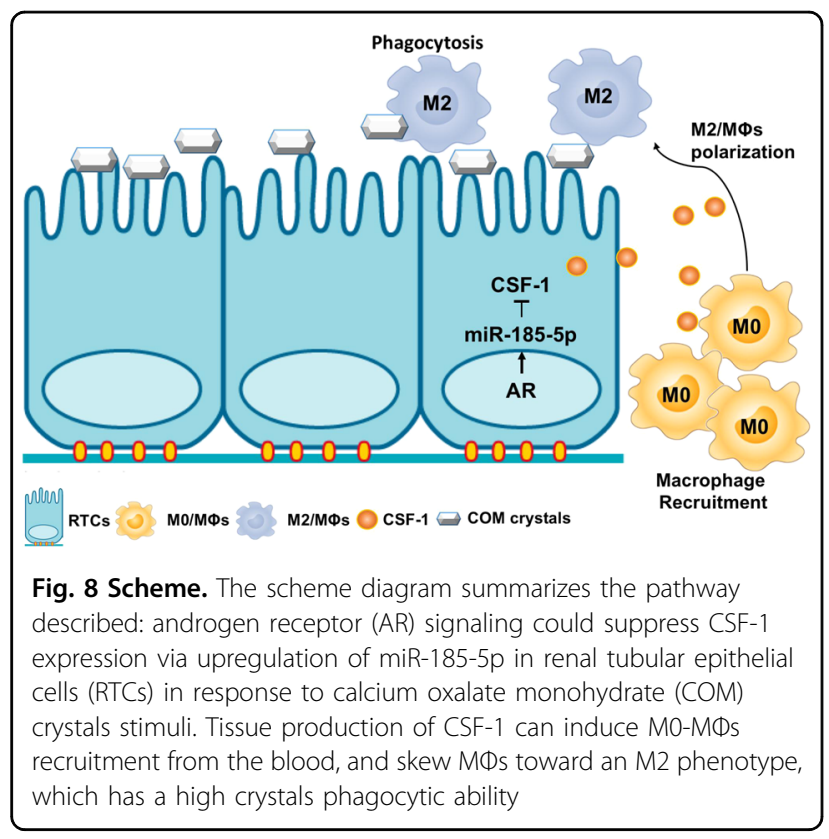

crystals deposition via altering the miRNA-185-5p/CSF1 signaling, which may provide clinicians a novel therapy to better suppress the renal $\mathrm{CaOx}$ crystals deposition.

\section{Materials and methods \\ Cell lines}

The human proximal tubular epithelial HK-2 cells, human embryonic kidney 293 cells (HEK-293), human monocyte THP-1 cells, mouse macrophage RAW264.7 cells and mouse cortical collecting duct M1 cells were purchased from the American Type Culture Collection (ATCC) (Rockville, MD). The human proximal tubular epithelial HKC-8 cells were kindly provided by Dr. Syed Khundmiri of the University of Louisville (Louisville, Kentucky). The HK-2, HKC-8, HEC-293, RAW-264.7, and M1 cells were maintained in Dulbecco's modified Eagle's media with 10\% fetal bovine serum (FBS) and 1\% penicillin/streptomycin. The THP-1 cells were cultured in RPMI-1640 media supplemented with $10 \%$ FBS. The THP-1 cells were differentiated to macrophages by treating with $100 \mathrm{ng} / \mathrm{ml}$ PMA for 3 days before being used in experiments.

\section{Lentiviral expression plasmid construction and virus production}

The shAR (pLKO.1-puro-shAR) was constructed with target sequence 5'-GTCGCGACTACTACAACTT-3' and shCSF-1 (pLKO.1-puro-shCSF-1) was constructed with target sequence 5'-TCTCCTGGTACAAGACATAAT-3' according to Addgene's protocol. The pLKO.1-shAR, pLKO.1-shCSF-1, pLVTHM-miR-15a-5p, pLVTHMmiR-130b-3p, pLVTHM-miR-185-5p, pLVTHM-miR650, or pLVTHM-miR-1207-5p, the psAX2 packaging plasmid, and $\mathrm{pMD} 2 \mathrm{G}$ envelope plasmid, were then transfected into HEK-293 cells using the standard calcium chloride transfection method for $48 \mathrm{~h}$ to get the lentivirus soup. The concentrated lentivirus soup was used immediately or frozen at $-80^{\circ} \mathrm{C}$ for later use.

\section{COM crystals preparation and staining}

COM crystals were prepared as described previously ${ }^{40}$. Briefly, $0.5 \mathrm{mM} \mathrm{Na}_{2} \mathrm{C}_{2} \mathrm{O}_{4}$ was mixed with $5 \mathrm{mM} \mathrm{CaCl}_{2}$ in a buffer containing $90 \mathrm{mM}$ Tris-HCL/pH7.4 and $10 \mathrm{mM}$ $\mathrm{NaCl}$. For staining, COM crystals were crystallized in the presence of $22.5 \mu \mathrm{g} / \mathrm{mL}$ Ponceau-S (Sigma-Aldrich; St. Louis, MO). The mixture was incubated at room temperature overnight and the COM crystals were harvested by a centrifugation at $2000 \mathrm{rpm}$ for $5 \mathrm{~min}$. The crystals pellets were washed in absolute methanol and then collected by another centrifugation at $2000 \mathrm{rpm}$ for $5 \mathrm{~min}$. The size of crystals generated by this protocol was 5-15 $\mu \mathrm{m}$. The crystals were then dried and decontaminated by UV light radiation overnight.

\section{Renal tubular cells exposure to COM crystals and collection of the $\mathrm{CM}$}

HK-2, HKC-8, and M1 cells (shAR or scr, or treated with varying concentrations of DHT or vehicle (ethanol)) were placed in $10 \mathrm{~cm}$ culture dishes, grown until close to confluent, washed with phosphate-buffered saline (PBS), and incubated with $20 \mu \mathrm{g} / \mathrm{cm}^{2}$ COM crystals. After $24 \mathrm{~h}$ of incubation, the cells were collected for qRT-PCR or western blot experiments, and the $\mathrm{CM}$ were collected for further experiments.

\section{Macrohahage recruitment assay}

Chambers with $5.0-\mu \mathrm{m}$ polycarbonate filter inserted in 24-well plates were used in the quantitative cell migration assays. In all, $1 \times 10^{5}$ PMA-differentiated-THP-1 macrophages (M0-MФs) or mouse RAW264.7 macrophages were plated onto the upper chambers, and the lower chambers were filled with the RTCs' CM. After 18- to 20-h incubation, the non-migrated cells in the upper chamber were removed and cells migrated into the membrane were fixed with methanol, stained with crystal violet, and photographed under an inverted microscope. Cell numbers were counted in five randomly chosen microscopic fields per membrane.

\section{Macrophage co-culture with the RTCs CM and evaluation of crystals phagocytosis}

The CM from RTCs were mixed with fresh RPMI media at a ratio of $1: 1$ and then added to M0-MФs or RAW264.7 macrophages for 3 days. To determine gene (MФs' markers) expression, MФs were collected in Trizol and analyzed as described below. For evaluation of COM crystals phagocytosis, the cells were maintained in normal RPMI media overnight and then treated with 
$15 \mu \mathrm{g} / \mathrm{cm}^{2}$ Ponceau-S labeled COM crystals for $24 \mathrm{~h}$. The percent of macrophages containing internalized Ponceau-S labeled COM crystals was then analyzed by optical microscopy.

\section{Quantification of CSF-1 in the CM}

CM was collected from HK-2, HKC-8, and M1 cells. ELISA kit (BOSTER) was used to measure CSF-1 concentrations in the CM according to the manufacturer's instructions.

\section{Quantification of CSF-1 in mice kidney homogenates}

We evaluated the levels of CSF-1 in kidney homogenates using an ELISA method as previously detailed ${ }^{41}$. In brief, the kidney tissues were homogenized by using a MixMill 300 (Qiagen). The protein $(200 \mu \mathrm{g} /$ tissue $)$ of each homogenate was determined using the $\mathrm{BCA}$ protein Asaay Kit. (Pierce). ELISA kit (BOSTER) was used to measure CSF-1 concentrations according to the manufacturer's instructions.

\section{RNA extraction and qRT-PCR analysis}

Total RNA was extracted by Trizol reagent (Invitrogen, CA) according to the manufacturer's instructions. RNAs $(1 \mu \mathrm{g})$ were subjected to reverse transcription using Superscript III transcriptase (Invitrogen). The qRT-PCR was conducted using a Bio-Rad CFX96 system with SYBR green to determine the mRNA expression level of a gene of interest. Expression levels were normalized to the expression of GAPDH, U6, or RPL32 RNA. Primers used are in the Supplementary Table 1.

\section{Antibodies}

The antibodies used in this study are listed in Supplementary Table 2.

\section{Flow cytometry analysis}

The CM from RTCs were mixed with fresh RPMI media at a ratio of 1:1 and then added to M0-MФs or RAW264.7 macrophages for 3 days. The identification and characterization of macrophage polarization were performed using flow cytometry. Cells were harvested, pre-incubated with the Fc receptor binding inhibitor antibody (Bioscience ${ }^{\mathrm{Tm}}$ ) for $10 \mathrm{~min}$ and thereafter incubated with phycoerythrin (PE)conjugated mouse anti-human CD206 and Fluorescein (FITC)-conjugated mouse anti-human CD163 for $60 \mathrm{~min}$. After washing the cells with flow cytometry staining buffer (Bioscience $\left.^{\mathrm{Tm}}\right)$, the expression of the cell surface markers CD206 and CD163 was analyzed using flow cytometry on FACSCalibur $^{\text {tm }}$ (BD Biosciences, USA).

\section{Western blot assay}

Total protein was extracted by RIPA buffer containing $1 \%$ protease inhibitors (Amresco, Cochran, USA). The immuno-positive bands were visualized with an ECL chemiluminescent detection system (Thermo Scientific), and the images were transferred to the Bio-Rad imaging system.

\section{ChIP assay}

Cell lysates were pre-cleared sequentially with normal rabbit IgG (sc-2027, Santa Cruz) and protein A-agarose. Then, $2.0 \mu \mathrm{g}$ anti-AR antibody was added to cell lysates and incubated at $4{ }^{\circ} \mathrm{C}$ overnight. For the negative control (NC), IgG was used. Specific primer sets designed to amplify a target sequence with the miRNA-185-5p promoter are listed in the Supplementary Table 3; PCR products were identified by agarose gel electrophoresis.

\section{Luciferase assay}

The fragment of CSF-1 3'-UTR containing two miR185-5p binding sites (sites 1 and 2) was amplified by PCR. The forward primer was 5'-CAGTAATTCTAGGCGA TCGCTGGACGCACAGAACAGTC-3', and the reverse primer was 5'-GATATTTTATTGCGGCCAGCTGTCG GCATCAGGACAGG-3'. The 3'-UTR of CSF-1 was constructed into psiCheck2 (Promega, Madison, WI, USA) by the Gibson assembly method. Cells were plated in 24-well plates and the complementary DNAs (cDNAs) were transfected using Lipofectamine (Invitrogen) according to the manufacturer's instructions. Luciferase activity was measured by Dual-Luciferase Assay (Promega) according to the manufacturer's instructions.

The miR-185-5p promoter region (1764 bp) was amplified from human genomic DNA by Phusion ${ }^{\circledR}$ HighFidelity DNA Polymerase (NEB, Beverly, NY) and ligased into Pgl3-basic vector (Promega) by the Gibson assembly method. For the ARE mutation, we designed the primer as forward: 5'-GACAGTGACCATGGCCAGGAGGAAG-3', reverse: 5'-GACCGACTATGTGGTCCTACTAGAA-3'; then used WT miR-185-5p promoter pGL3 plasmid as the template to run PCR and performed self-ligation. For luciferase assay, cells were plated in 24-well plates and the cDNA transfected using Lipofectamine3000 (Invitrogen) according to the manufacturer's instructions. pRL-TK was used as internal control. Luciferase activity was measured by Dual-Luciferase Assay (Promega) according to the manufacturer's manual.

\section{Generation of Cdh16-ARKO mice with renal CaOx crystals formation/adhesion}

All of the mouse experiments were performed under protocols approved by the Institutional Animal Care and Use Committee of the University of Rochester Medical Center. We generated ARKO mice that lacked AR gene in the RTCs via mating loxP site-AR female transgene $\left(\mathrm{AR}^{\text {flox/flox }} \mathrm{C} 57 / \mathrm{B} 6\right)$ mice with cadherin 16 promoterdriven Cre (Cdh16-cre; C57/B6; The Jackson Laboratory) male mice expressing heterozygous $\mathrm{Cre}$ recombinase gene 
under the control of a tissue-specific promoter, KspCdh16, which was exclusively expressed in $\mathrm{RTCs}^{42}$. Tail genotyping followed methods in previous reports ${ }^{19,43}$.

We then established the renal $\mathrm{CaOx}$ crystals formation/ adhesion mouse model following the reported protocol ${ }^{44}$. The 8-week-old male mice were given daily intraabdominal injections of $80 \mathrm{mg} / \mathrm{kg}$ glyoxylate for 6 days. All animals had free access to chow and water.

\section{Development of hyperoxaluria-induced intrarenal $\mathrm{CaOx}$ crystals deposition in rat and ASC-J9 ${ }^{\circledR}$ treatment}

Eight-week-old Sprague-Dawley male rats (180-200 g) were divided into three groups (six rats/group) and all were given chow mixed with 5\% HLP (weight/weight HLP/chow) for 8 weeks. After 4 weeks administration of HLP, rats were injected with ASC-J9 ${ }^{\circledR}(37.5 \mathrm{mg} / \mathrm{kg} / 48 \mathrm{~h}$ i. p.) or control vehicle DMA, and AgomiR-185-5p or AgomiR-negative control ( $15 \mathrm{nmol} / \mathrm{kg} /$ week) for 4 weeks. The AgomiRs were synthesized by Ribobio Inc. (Guangzhou, China). Next, the rats were sacrificed, and kidneys were obtained for analyses.

\section{Observation of intrarenal $\mathrm{CaOx}$ crystals deposition}

The renal crystals formation/adhesion was examined using Pizzolato staining, as described previously ${ }^{45}$, and quantitatively assessed using Image J software.

\section{Histology and IHC}

Kidneys from mice or rats were fixed for $72 \mathrm{~h}$ with $10 \%$ buffered formalin before embedding in paraffin. Serial sections at $5 \mu \mathrm{m}$ thick were obtained for histologic analysis. Hematoxylin and eosin $(\mathrm{H} \& \mathrm{E})$ staining involved standard procedures.

For IHC, sections were incubated with the primary antibodies. To enhance antigen exposure, the slides were treated with $10 \mathrm{mM}$ sodium citrate/pH 6.0 at $98{ }^{\circ} \mathrm{C}$ for $20 \mathrm{~min}$ for antigen retrieval. The slides were incubated with endogenous peroxidase blocking solution, and then were incubated with the primary antibody at $4{ }^{\circ} \mathrm{C}$ overnight. After rinsing with PBS, the slides were incubated for $45 \mathrm{~min}$ with biotin-conjugated secondary antibody, washed, and then incubated with enzyme conjugate horseradish peroxidase (HRP)-streptavidin. Freshly prepared and 3,3'-diaminobenzidine (DAB) (Zymed, South San Francisco, CA) was used as substrate to detect HRP. Finally, slides were counterstained with H\&E and mounted with aqueous mounting media. Positive cells were calculated as the number of immunopositive cells $\times 100 \%$ divided by total number of cells/field in 10 random fields at $\times 400$ magnification.

The macrophages subtypes were detected by immunofluorescence staining for CD206 using frozen sections. Frozen sections $(8 \mu \mathrm{m})$ were fixed in $10 \%$ buffered formalin for $15 \mathrm{~min}$. After washing with PBS containing $0.3 \%$
Triton X-100 for $15 \mathrm{~min}$, the sections were incubated with the primary antibody at $4{ }^{\circ} \mathrm{C}$ overnight. After rinsing with PBS, the sections were then incubated for $1 \mathrm{~h}$ at room temperature with Alexa Fluor-conjugated 488-secondary antibodies, 1:1000 (ThermoFisher). Finally, the sections were washed, counterstained with nuclear marker 4',6diamidino-2-phenylindole (DAPI) and wet mounted. All images were obtained using a fluorescence microscope.

\section{MISH assay}

The in situ hybridization for miRNAs was performed on fixed paraffin-embedded sections as previously described $^{46,47}$. Oligonucleotide probes complementary to mouse-miR-185-5p were purchased from the Exonbio Lab (Guangzhou, China). The probe sequences were as follows: 5'-TCAGGAACTGCCTTTCTCTCCA-3'. These oligonucleotides contain 2'-fluoro-modified RNA residues ( $2^{\prime}$-F RNA) at the 3, 6, 15, and 20 bases. Both $5^{\prime}$ and $3^{\prime}$ ends were labeled by digoxin (DIG). In general, $10 \mu \mathrm{m}$ thick sections from kidney tissues were deparaffinized, dehydrated, and subsequently immersed in $0.2 \mathrm{M} \mathrm{HCl}$ for 15 min. Slides were then immersed in PBS solution. Proteinase K (working solution: $200 \mu \mathrm{g} / \mathrm{ml}$ in PBS) digestion was used to treat tissues at $37^{\circ} \mathrm{C}$ for $5 \mathrm{~min}$. After digestion, slides were immersed in RNase-free water for 5 min and air dried. The slides were then prehybridized in hybridization buffer (Exonbio Lab, Guangzhou, China) at $37^{\circ} \mathrm{C}$ for $2 \mathrm{~h}$, followed by the hybridization with probe at $37^{\circ} \mathrm{C}$ for $48 \mathrm{~h}$. After hybridization, slides were washed $2 \times$ SCC with $0.5 \%$ Tween-20 twice for $5 \mathrm{~min}$ at room temperature. DNA was counterstained with DAPI $(1 \mathrm{mg}$ / $\mathrm{ml})$. Images of miRNA signals in slides were captured by fluorescent microscope. For quantitative assessments, the images were analyzed by using Image J software.

\section{Statistics}

All statistical analyses were carried out with SPSS 13.0 (SPSS Inc., Chicago, IL). The data values were presented as the mean $\pm \mathrm{SD}$. The data were first analyzed for normal distribution by using Kolmogorov-Smirnov test. Differences in normally distributed variables were analyzed by two-tailed Student's $t$-test or one-way analysis of variance (ANOVA) followed by Bonferroni multiple comparison test. Differences were assessed by Mann-Whitney $U$-test for non-normally distributed variables. A two-sided $P<0.05$ was considered statistically significant.

\section{Acknowledgements}

This work was supported by NIH grants (CA155477 and CA156700), George Whipple Professorship Endowment and Taiwan Ministry of Health and Welfare Clinical Trial and Research Center of Excellence (MOHW104-TDU-B-212-

113002), and by grants from National Natural Science Foundation, China (no. 81800625 and no. 81670643), and Natural Science Foundation of Guangdong Province (2018A030310296). We thank Karen Wolf for helping in preparing the manuscript. 


\section{Author details}

'Department of Urology and Guangdong Key Laboratory of Urology, The First Affiliated Hospital of Guangzhou Medical University, 510230 Guangzhou, China. ${ }^{2}$ George Whipple Lab for Cancer Research, Departments of Pathology, Urology, and Radiation Oncology, and The Wilmot Cancer Institute, University of Rochester Medical Center, Rochester, NY 14646, USA. ${ }^{3}$ Departments of Medicine, University of Rochester Medical Center, Rochester, NY 14646, USA. ${ }^{4}$ Sex Hormone Research Center, China Medical University/Hospital, Taichung 404, Taiwan

\section{Authors' contributions}

C.C. and G.Z. designed the study concept and experiments. W.Z. and S.Y. designed experiments and provided reagents. W.Z., Z.Z., L.Z., T.L. and F.Z. performed the experiments. W.Z., D.B. and C.C. wrote the paper.

\section{Conflict of interest}

The authors declare that they have no conflict of interest.

\section{Publisher's note}

Springer Nature remains neutral with regard to jurisdictional claims in published maps and institutional affiliations.

Supplementary Information accompanies this paper at (https://doi.org/ 10.1038/s41419-019-1358-y).

Received: 13 August 2018 Revised: 5 December 2018 Accepted: 18 December 2018

Published online: 20 March 2019

\section{References}

1. Scales, C. D., Smith, A. C., Hanley, J. M. \& Saigal, C. S. Prevalence of kidney stones in the United States. Eur. Urol. 62, 160-165 (2012).

2. Xu, H., Zisman, A. L., Coe, F. L. \& Worcester, E. M. Kidney stones: an update on current pharmacological management and future directions. Expert. Opin. Pharmacother. 14, 435-447 (2013).

3. Benz-Bohm, G. \& Hoppe, B. Urolithiasis and nephrocalcinosis. in Pediatric Uroradiology pp. 385-400 (Springer, Berlin, Heidelberg, 2008).

4. Grover, P. K. et al. Intracrystalline urinary proteins facilitate degradation and dissolution of calcium oxalate crystals in cultured renal cells. AJP Ren. Physiol. 294, F355-F361 (2007).

5. Taguchi, K. et al. Colony-stimulating factor-1 signaling suppresses renal crystal formation. J. Am. Soc. Nephrol. 25, 1680-1697 (2014).

6. Kusmartsev, S. et al. Calcium oxalate stone fragment and crystal phagocytosis by human macrophages. J. Urol. https://doi.org/10.1016/j.juro.2015.11.048 (2015).

7. Vervaet, B. A., Verhulst, A., Dauwe, S. E., De Broe, M. E. \& D'Haese, P. C. An active renal crystal clearance mechanism in rat and man. Kidney Int. 75, 41-51 (2009).

8. Taguchi, K. et al. Proinflammatory and metabolic changes facilitate renal crystal deposition in an obese mouse model of metabolic syndrome. J. Urol. 194, 1787-1796 (2015)

9. Naghii, M. R., Babaei, M. \& Hedayati, M. Androgens involvement in the pathogenesis of renal stones formation. PLoS ONE 9, e93790 (2014).

10. Li, J.-Y. et al. Testosterone and androgen receptor in human nephrolithiasis. J. Urol. 184, 2360-2363 (2010).

11. Zeng, G. et al. Prevalence of kidney stones in China: an ultrasonography based cross-sectional study. BJU Int. https://doi.org/10.1111/bju.13828 (2017).

12. Liang, L. et al. Androgen receptor enhances kidney stone-CaOx crystal formation via modulation of oxalate biosynthesis \& oxidative stress. Mol. Endocrinol. 28, 1291-1303 (2014).

13. Chen, W. C. et al. The association of androgen- and oestrogen-receptor gene polymorphisms with urolithiasis in men. BJU Int. 88, 432-436 (2001).

14. Okada, A. et al. Renal macrophage migration and crystal phagocytosis via inflammatory-related gene expression during kidney stone formation and elimination in mice: detection by association analysis of stone-related gene expression and microstructural observation. J. Bone Miner. Res. 25, 2701-2711 (2010).
15. Hume, D. A. \& MacDonald, K. P. A. Therapeutic applications of macrophage colony-stimulating factor-1 (CSF-1) and antagonists of CSF-1 receptor (CSF-1R) signaling. Blood 119, 1810-1820 (2012).

16. Solary, E. When monocyte life hangs by a thread. Blood 119, 2699-2700 (2012).

17. Sica, A. \& Mantovani, A. Macrophage plasticity and polarization: in vivo veritas. J. Clin. Invest. 122, 787-795 (2012).

18. Kanlaya, R., Sintiprungrat, K., Chaiyarit, S. \& Thongboonkerd, V. Macropinocytosis is the major mechanism for endocytosis of calcium oxalate crystals into renal tubular cells. Cell Biochem. Biophys. 67, 1171-1179 (2013).

19. Shao, X., Somlo, S. \& Igarashi, P. Epithelial-specific Cre/lox recombination in the developing kidney and genitourinary tract. J. Am. Soc. Nephrol. 13, 1837-1846 (2002).

20. Lin, H. - H. et al. The macrophage F4/80 receptor is required for the induction of antigen-specific efferent regulatory $T$ cells in peripheral tolerance. J. Exp. Med. 201, 1615-1625 (2005).

21. Khan, S. R. Nephrocalcinosis in animal models with and without stones. Urol. Res. 38, 429-438 (2010).

22. Khan, S. R., Glenton, P. A. \& Byer, K. J. Modeling of hyperoxaluric calcium oxalate nephrolithiasis: experimental induction of hyperoxaluria by hydroxy-Lproline. Kidney Int. 70, 914-923 (2006).

23. Wang, R. et al. ASC-J9( $\left.{ }^{\circledR}\right)$ suppresses castration resistant prostate cancer progression via degrading the enzalutamide-induced androgen receptor mutant AR-F876L. Cancer Lett. 379, 154-160 (2016).

24. Shang, Z. et al. Antiandrogen therapy with hydroxyflutamide or androgen receptor degradation enhancer ASC-J9 enhances BCG efficacy to better suppress bladder cancer progression. Mol. Cancer Ther. 14, 2586-2594 (2015).

25. Wang, R. et al. Preclinical study using Malat1 small interfering RNA or androgen receptor splicing variant 7 degradation enhancer ASC-J9( $\left.{ }^{\circledR}\right)$ to suppress enzalutamide-resistant prostate cancer progression. Eur. Urol. https:// doi.org/10.1016/j.eururo.2017.04.005 (2017).

26. Yang, Z. et al. ASC-J9 ameliorates spinal and bulbar muscular atrophy phenotype via degradation of androgen receptor. Nat. Med. 13, 348-353 (2007).

27. Huang, C.-K. et al. New therapy via targeting androgen receptor in monocytes/macrophages to battle atherosclerosis. Hypertens. Dallas Tex. $19796 \mathbf{6 3}$ 1345-1353 (2014).

28. Huang, C.-K. et al. Androgen receptor promotes abdominal aortic aneurysm development via modulating inflammatory interleukin-1a and transforming growth factor- $\beta 1$ expression. Hypertens. Dallas Tex. 1979 66, 881-891 (2015).

29. Mulay, S. R. \& Anders, H.-J. Crystal nephropathies: mechanisms of crystalinduced kidney injury. Nat. Rev. Nephrol. 13, 226-240 (2017).

30. Aggarwal, K. P. Narula, S., Kakkar, M. \& Tandon, C. Nephrolithiasis: molecula mechanism of renal stone formation and the critical role played by modulators. Biomed. Res. Int. 2013, 1-21 (2013).

31. Verkoelen, C. F. Crystal retention in renal stone disease: a crucial role for the glycosaminoglycan hyaluronan? J. Am. Soc. Nephrol. 17, 1673-1687 (2006).

32. Duffield, J. S. Macrophages in kidney repair and regeneration. J. Am. Soc Nephrol. 22, 199-201 (2011).

33. Zhang, M.-Z. et al. CSF-1 signaling mediates recovery from acute kidney injury. J. Clin. Invest. 122, 4519-4532 (2012).

34. Perry, H. M. \& Okusa, M. D. Driving change: kidney proximal tubule CSF-1 polarizes macrophages. Kidney Int. 88, 1219-1221 (2015)

35. Meur, Y. L. et al. Macrophage accumulation at a site of renal inflammation is dependent on the M-CSF/c-fms pathway. J. Leukoc. Biol. 72, 530-537 (2002)

36. Wang, $Y$. et al. Proximal tubule-derived colony stimulating factor-1 mediates polarization of renal macrophages and dendritic cells, and recovery in acute kidney injury. Kidney Int. 88, 1274-1282 (2015).

37. Okada, A. et al. Genome-wide analysis of genes related to kidney stone formation and elimination in the calcium oxalate nephrolithiasis model mouse: detection of stone-preventive factors and involvement of macrophage activity. J. Bone Miner. Res. 24, 908-924 (2009).

38. de Water, R. et al. Role of macrophages in nephrolithiasis in rats: an analysis of the renal interstitium. Am. J. Kidney Dis. 36, 615-625 (2000).

39. Wang, R. et al. ASC-J9( $\left.{ }^{\circledR}\right)$ suppresses castration resistant prostate cancer progression via degrading the enzalutamide-induced androgen receptor mutant AR-F876L. Cancer Lett. 379, 154-160 (2016).

40. Chaiyarit, S., Mungdee, S. \& Thongboonkerd, V. Non-radioactive labelling of calcium oxalate crystals for investigations of crystal-cell interactions and internalization. Anal. Methods 2, 1536 (2010).

41. Menke, J. et al. Distinct roles of CSF-1 isoforms in lupus nephritis. J. Am. Soc Nephrol. 22, 1821-1833 (2011). 
42. Shao, X., Somlo, S. \& Igarashi, P. Epithelial-specific Cre/lox recombination in the developing kidney and genitourinary tract. J. Am. Soc. Nephrol. 13, 1837-1846 (2002).

43. Yeh, S. et al. Generation and characterization of androgen receptor knockout (ARKO) mice: an in vivo model for the study of androgen functions in selective tissues. Proc. Natl. Acad. Sci. USA 99, 13498-13503 (2002).

44. Okada, A. et al. Successful formation of calcium oxalate crystal deposition in mouse kidney by intraabdominal glyoxylate injection. Urol. Res. 35, 89-99 (2007).
45. PIZZOLATO, P. Histochemical recognition of calcium oxalate. J. Histochem. Cytochem. 12, 333-336 (1964).

46. Li, G. et al. miRNA-223 upregulated by MYOD inhibits myoblast proliferation by repressing IGF2 and facilitates myoblast differentiation by inhibiting ZEB1. Cell Death Dis. 8, e3094 (2017).

47. Li, J. et al. microRNA-146 up-regulation predicts the prognosis of non-small cell lung cancer by miRNA in situ hybridization. Exp. Mol. Pathol. 96, 195-199 (2014). 